\title{
OnabotulinumtoxinA for trigeminal neuralgia: a review of the available data
}

\author{
Toxina Onabotulínica-A para neuralgia do trigêmeo: uma revisão dos dados disponíveis \\ Pedro A. Kowacs ${ }^{1,2}$, Marco A. T. Utiumi², Fábio A. Nascimento³, Elcio J. Piovesan², Helio A. G. Teive²
}

\begin{abstract}
Trigeminal neuralgia (TN) patients may develop side effects from centrally acting drugs, have contraindications for neurosurgical procedures, or experience relapse during conventional therapies. OnabotulinumtoxinA (BoNT/A) has been reported to be effective for TN, although this finding has been challenged. An overview of the available evidence based on a narrative/qualitative analysis of the literature is presented. About $90 \%$ of patients who receive BoNT/A show an improvement, a higher figure than that reported for the placebo effect of BoNT/A for other headaches. Tolerability of BoNT/A is good, and its few side-effects are transient. The articles reviewed were mainly case reports, case series and open-label trials; however, randomized controlled trials have endorsed the efficacy of BoNT/A for TN. This evidence, together with a better understanding of the analgesic mechanisms of BoNT/A and its proven efficacy in treating other pain syndromes, supports the use of this toxin as a therapeutic option for TN.
\end{abstract}

Keywords: trigeminal neuralgia, botulinum neurotoxin type A, botulinum-A toxin, onabotulinumtoxinA, neuropathic pain.

RESUMO

Pacientes com neuralgia do trigêmeo (NT) podem apresentar efeitos colaterais decorrentes do uso de drogas psicoativas, contra-indicações a procedimentos neurocirúrgicos ou perda da eficácia destas terapias. A neurotoxina botulínica do tipo A (NTB/A) tem demonstrado ser eficaz no alívio da NT, ainda que este achado tenha sido contestado. Uma análise narrativa/qualitativa da literatura disponível é apresentada. Cerca de $90 \%$ dos pacientes que receberam NTB/A melhoram, um número superior aos atribuíveis ao efeito placebo da NTB/A em outras cefaléias. Além disso, a NTB/A mostrou uma baixa incidência de efeitos colaterais, transitórios. Embora a maioria dos artigos consistam de relatos de caso, séries de casos e ensaios abertos, ensaios clínicos randomizados controlados recentes reafirmam a eficácia da NTB/A na NT. Estas evidências, associadas ao melhor entendimento dos mecanismos analgésicos da NTB/A e a sua eficácia em outras síndromes dolorosas, ratificam a NTB/A como uma opção terapêutica para a NT.

Palavras-chave: neuralgia do trigêmeo, neurotoxina botulínica do tipo A, toxina botulínica do tipo A, toxina onabotulinica A, dor neuropática.

Trigeminal neuralgia (TN) is a unilateral disorder characterized by brief electric-shock-like attacks of pain, abrupt in onset and termination and limited to the distribution of one or more divisions of the trigeminal nerve ${ }^{1}$. It is reported to have a prevalence of 0.1-0.2 per thousand and an incidence ranging from about 2 to 7.1/100 000/year and extending up to 20/100 000/year in individuals over 60 years of age. The condition is more common in women than in men (ratio 3:2) ${ }^{2}$. Treatment includes pharmacological therapy, usually with membrane stabilizers; invasive or minimally-invasive (mainly percutaneous procedures) surgical therapies; and radiosurgery ${ }^{3}$. In 2005, OnabotulinumtoxinA (BoNT/A) was reported to be effective for cases of TN that failed to respond to other therapies. ${ }^{4}$. The therapeutic effect of BoNT/A in TN was first mentioned after a serendipitous finding by Wang and Jankovic ${ }^{5}$. Reporting a case similar to the one that motivated a previous study by our group ${ }^{4}$, Jankovic described a patient who presented with hemifacial spasm and TN whose TN improved after treatment of the hemifacial spasm with BoNT/A. Since then, case reports and case series have been published in neurology, headache, pharmacology and pain medicine journals ${ }^{6,78,9,10,11,12,13,14}$. This literature, although suggesting the therapeutic effects of BoNT/A in TN, has been challenged ${ }^{15}$ or even ignored by panels of experts ${ }^{16,17}$.

The present review was undertaken to give readers an overview of the available evidence that BoNT/A has a therapeutic effect on TN.

${ }^{1}$ Instituto de Neurologia de Curitiba, Curitiba PR, Brazil;

universidade Federal do Paraná, Hospital de Clínicas, Serviço de Neurologia, Curitiba PR, Brazil.

${ }^{3}$ University of Toronto, Toronto Western Hospital, Division of Neurology, Toronto Ontario, Canada.

Correspondence: Pedro André Kowacs; Instituto de Neurologia de Curitiba; Rua Jeremias Maciel Perretto, 300; 81210-310 Curitiba PR, Brasil;

E-mail:pkowacs@gmail.com

Conflict of Interest: Dr. Kowacs has been a member of the board of the Latin American expert committee for Allergan. Dr. Teive has been a member of the board of the Latin American expert committee for Allergan and has given lectures and workshops for Allergan. Dr. Piovesan has given a lecture for Allergan. Drs. Teive and Piovesan are in charge of the HC-UFPR botulinum toxin outpatient clinic.

Received 20 March 2015; Received in final form 23 April 2015; Accepted 12 May 2015. 
BOTULINUM NEUROTOXIN AS A THERAPEUTIC OPTION FOR TN

TN usually starts after the age of $60^{2,3}$. In this older age group the disease poses therapeutic problems from a pharmacological and surgical standpoint because patients may develop side effects from centrally acting drugs and have contraindications for neurosurgical procedures. Furthermore, relapse may occur after surgery, and some patients may refuse additional invasive procedures. In this scenario, BoNT/A injections can be considered a therapeutic option for TN. The body of data presented below (Table) shows that most patients benefit from BoNT/A injections, as $213(89.9 \%)$ of the 237 patients described in the studies in our review reported improvements.

Side effects reported consisted mainly of mild and transient facial paresis, which occurred after at least one injection session and was reported by Zúñiga et al. (1/12 and 2/20 patients) ${ }^{14,18}$, Allam et al. $(1 / 1)^{8}$, Borodic and Acquadro (proportion not reported $)^{7}$, Ngeow and Nair $(1 / 1)^{19}$, Bohluli et al. $(3 / 15)^{20}$, Wu et al. $(5 / 22)^{21}$, Li et al. $(10 / 88)^{22}$, Shehata et al. $(4 / 10)^{23}$ and Zhang et al. $(3 / 53)^{24}$. Temporary dysesthesia (1/8) and difficulties chewing on the side of the injection $(1 / 8)$ were reported by Turk et $\mathrm{al}^{9}$. Transient local edema was reported by Wu et al. $(2 / 22)^{21}$, Li et al. $(3 / 88)^{22}$ and Zhang et al. $(2 / 53)^{24}$. Local hematoma was reported by Zúñiga et al. $(2 / 20)^{18}$. Of the patients reported by our group, three presented with facial asymmetry $(3 / 13)$ and one with ptosis $(1 / 13)^{4}$. It should be noted that two of our patients who did not belong to our original cohort developed infectious complications (a hard palate abscess and a retropharyngeal abscess) from intra-oral BoNT/A injections. Both patients had had injections in their dental arches. The abscesses resolved with no further complications after antimicrobial therapy, but the fact that this complication occurred prompted us to stop injecting BoNT/A in the dental arches and gums. This complication was not reported by Li et al. ${ }^{22}$ or Zhang et al..$^{24}$, whose studies included some patients who received BoNT/A submucosally. None of the patients in the studies by Boscá-Blasco et al. $(\mathrm{n}=4)^{11}$, Felicio et al. $(n=1)^{13}$, Micheli et al. $(n=1)^{6}$, Uluduz et al. $(n=1)^{12}$, Volcy et al. $(n=1)^{10}$ reported any side effects. Overall, tolerability was good and operator-dependent effects and side effects were probably related more to the "learning curve" associated with the use of BoNT/A. With practice, these problems would, therefore, probably be eliminated.

However, the use of BoNT/A as a therapeutic option for treating TN has several drawbacks: a) there is a shortage of double-blind trials; b) the method is operator-dependent; c) there are no consensus guidelines; and d) "refractory trigeminal neuralgia" is a concept that has yet to be defined.

Nonetheless, none of these drawbacks seem to justify the rejection of BoNT/A as a therapeutic option for TN. Indeed, many of the medications used to treat TN started being used without a double-blind trial. The efficacy of BoNT/A in TN (about $90 \%$ of patients reported an improvement) was not achieved in double-blind trials involving BoNT/A for other head pains, as discussed below.

A few recent randomized, double-blind, placebo-controlled trials provide the best evidence for the efficacy of BoNT/A in TN. A study by Wu et al. ${ }^{21}$ and $\mathrm{Wu}$ and $\mathrm{Lian}^{25}$ included 39 patients with classical TN according to the ICHD-2 criteria ${ }^{1}$ who failed to respond to conventional treatment (mean Visual Analog Scale or VAS score $\geq 4$, mean attack frequency $\geq 4$ per day) after neuroimaging findings ruled out any structural pathology. All the patients' medication was maintained during the study period. Patients were excluded if they had skin problems at injection sites, were pregnant, were nursing mothers, were planning a pregnancy, were unable to use a reliable contraceptive method, had a medical condition or were using drugs that could interact negatively with BoNT/A. They were followed up for 12 weeks post-treatment. A period of 12 weeks was chosen as this is the typical duration of the motor effects of BoNT/A. Intradermal and/or subcutaneous injections of $75 \mathrm{U}$ of BoNT/A $(5 \mathrm{U} / 0.1 \mathrm{~mL})$ were applied at 15 points $(0.1 \mathrm{~mL}$ per point). The primary endpoints were pain attack frequency and pain severity, which were significantly affected as early as the first and second weeks, respectively $(\mathrm{p}<0.05)$. Shehata et al. ${ }^{23}$ studied 20 subjects with intractable idiopathic TN, which they defined as a failure to achieve a $50 \%$ relief in pain intensity quantified by VAS and/or the frequency of paroxysms during the previous three months. Subjects who were pregnant, had symptomatic TN (abnormal neurological examination or MRI) and were potentially unreliable during follow-up were excluded. The active treatment arm consisted of 10 patients who received $0.1 \mathrm{~mL}$ of BoNT/A (5 U/0.1 mL) applied subcutaneously per point (total dose ranged from 40 to $60 \mathrm{U}$ ) using a "follow the pain" method. After 12 weeks significant reductions in VAS scores (a decrease of 6.5 compared with 0.3 for saline) and the frequency of paroxysms were observed (both were recorded in the second week and were sustained over the follow-up period). Zúñiga et al. ${ }^{18}$ reported 36 cases of subjects suffering from classical TN, some of whom had not responded satisfactorily to conventional treatments. The BoNT/A group consisted of 20 subjects who received $50 \mathrm{U}$ of the toxin subcutaneously in various sites $1 \mathrm{~cm}$ apart. Subjects with involvement of the third branch of the trigeminal nerve received $10 \mathrm{U}$ intramuscularly in the masseter muscle. At 1 month, the active treatment group reported fewer paroxysms of pain $(p=0.036)$. At 2 months, subjects in this group who were taking carbamazepine also showed reduced VAS scores $(p=0.02)$. At 3 months, the improvement in mean VAS score and number of paroxysms was sustained in the BoNT/A group ( $p=0.01$ and $p=0.006$ ). There was no difference in functional impact scores between the BoNT/A and placebo groups. Finally, Zhang et al..$^{24}$ studied the effects of different dosages of BoNT/A in 84 patients with classical $\mathrm{TN}$ who had failed to respond to recent treatment for $\mathrm{TN}$ (mean pain intensity score $\geq 4$, mean attack frequency $\geq 4$ /day; course $>4$ months) and were randomized to receive saline, $25 \mathrm{U} / \mathrm{mL}$ or $75 \mathrm{U} / \mathrm{mL}$ of BoNT/A intradermally and/or 
Table. Reports on the efficacy of BoNT/A for trigeminal neuralgia.

\begin{tabular}{|c|c|c|c|c|}
\hline Author, year & $\begin{array}{c}\text { Type of } \\
\text { Publication }\end{array}$ & BoNT/A therapy & $\begin{array}{l}\text { Number of cases, } \\
\text { response }\end{array}$ & Type of measurement, $p$ \\
\hline $\begin{array}{l}\text { Wang and } \\
\text { Jankovic, 1998*5 }\end{array}$ & Mention & & $1 / 1$ & Patient report \\
\hline $\begin{array}{l}\text { Micheli et al., } \\
2002 .^{6}\end{array}$ & Case report & $\begin{array}{c}2.5 \mathrm{MU} \text { in } 5 \text { sites }(12.5 \mathrm{U}) \text { at } 12 \\
\text { wk intervals }\end{array}$ & $1 / 1$ & Patient report \\
\hline $\begin{array}{l}\text { Borodic and } \\
\text { Acquadro, 2002.? }\end{array}$ & Case series & $30-50 \cup$ & $8 / 11$ & Patient report \\
\hline $\begin{array}{l}\text { Piovesan et al., } \\
2005 .{ }^{4}\end{array}$ & Open-label trial & $\begin{array}{c}\text { 6.45-9.11 U per branch } \\
\left(3.3 \mathrm{U} / \mathrm{cm}^{2}\right)\end{array}$ & $13 / 13$ & Pain area, $p<0.0001$ (at 60 days); VAS, $p=N R$ \\
\hline Türk et al., 2005.9 & Open-label trial & $50 \mathrm{U}$ in 2 sites (BoNT/A) & $8 / 8$ & $\begin{aligned} \text { VAS, } p= & 0.011 \text { and Frequency, } p=0.012 \\
& \left(\text { at } 1^{\text {st }} \mathrm{wk}, 2^{\text {nd }} \mathrm{mo}, 6^{\text {th }} \mathrm{mo}\right)\end{aligned}$ \\
\hline Allam et al., $2005 .{ }^{8}$ & Case report & $2 \mathrm{U}$ in 8 points $(16 \mathrm{U})(\mathrm{BoNT} / \mathrm{A})$ & $1 / 1$ & $V A S, p=N R$ \\
\hline $\begin{array}{l}\text { Boscá-Blasco et } \\
\text { al., 2006*.11 }\end{array}$ & Case series & $17.5 \mathrm{U}$ at $6 \mathrm{mo}$ intervals & $4 / 4$ & PAS, $p=N R$ \\
\hline Volcy et al., 2006.10 & Case report & $6-7.5 \cup$ at 4 mo intervals & $1 / 1$ & Patient report \\
\hline $\begin{array}{l}\text { Uluduz et al., } \\
2007 .^{12}\end{array}$ & Case report & $75 \cup$ at 3 mo intervals & $1 / 1$ & Patient report \\
\hline $\begin{array}{l}\text { Felicio et al., } \\
2007 * 13\end{array}$ & Case report & $100 \mathrm{U}$ at 2 mo intervals & $1 / 1$ & Patient report \\
\hline $\begin{array}{l}\text { Zúñiga et al., } \\
2008 .^{14}\end{array}$ & Open-label trial & $20-50 \cup(B \circ N T / A)$ & $10 / 12$ & VAS, $p=N R$ and Frequency, $p=N R$ (during $8 w k$ ) \\
\hline $\begin{array}{l}\text { Ngeow and Nair, } \\
2010 .^{19}\end{array}$ & Case report & $\begin{array}{l}100 \cup \text { divided into two sites } \\
\text { (BoNT/A) }\end{array}$ & $1 / 1$ & Patient report \\
\hline Yoon et al., 2010.38 & Case report & $10 \cup(\mathrm{BoNT} / \mathrm{A})$ & $1 / 1$ & $\begin{array}{c}\text { Patient report and current perception threshold } \\
\text { measurements at } 2 \text { mo }\end{array}$ \\
\hline $\begin{array}{l}\text { Bohluli et al., } \\
2011 .{ }^{20}\end{array}$ & Open-label trial & $\begin{array}{l}\text { 50-100 } \cup \text { injected at each } \\
\text { trigger zone }\end{array}$ & $15 / 15$ & $\begin{array}{c}\text { VAS, } p<0.001 \text { and Frequency, } p<0.001 \\
\text { (at } 1^{\text {st }} \text { wk and } 1^{\text {st }} \text { mo); Global assessment, } p<0.001 \\
\text { (at } 6 \text { mo) }\end{array}$ \\
\hline Wu et al., $2012 .{ }^{21}$ & $\mathrm{RCT}$ & $\begin{array}{l}75 \cup \text { injected at } 15 \text { points } \\
\text { (BoNT/A) }\end{array}$ & $15 / 22$ responders & $\begin{array}{c}\text { VAS, } p<0.05 \text { (from } 2^{\text {nd }} w k \text { to } 12^{\text {th }} w k \text { ); Responders } \\
(\geq 50 \% \text { reduction), } p<0.01 ; \text { Frequency, } p<0.05 \\
\text { (from } 1^{\text {st }} w k \text { to } 12^{\text {th }} w k \text { ); PGIC, } p<0.01\end{array}$ \\
\hline $\begin{array}{l}\text { Shehata et al., } \\
2013 .^{23}\end{array}$ & $\mathrm{RCT}$ & $\begin{array}{l}\text { 40-60 } \cup(5 \cup \text { per point) in a "follow } \\
\text { the pain method" (BoNT/A) }\end{array}$ & Proportion NR & $\begin{array}{c}\text { VAS, } p<0.0001 \text { and Frequency, } p<0.0001 \text { (from } \\
2^{\text {nd }} w k \text { to } 12^{\text {th }} w k \text { ); } Q \text { Q L }, p<0.0001\end{array}$ \\
\hline $\begin{array}{l}\text { Zúñiga et al., } \\
\text { 2013.18 }\end{array}$ & $\mathrm{RCT}$ & $\begin{array}{l}50 \cup \text { subcutaneously with } \\
\text { additional } 10 \mathrm{U} \text { in the masseter if } \\
\text { there is } \mathrm{V} 3 \text { involvement (BoNT/A) }\end{array}$ & Proportion NR & $\begin{array}{c}\text { VAS, } p=0.01 \text { (at } 3 \text { mo); Frequency, } p=0.036,0.01 \\
0.006 \text { (at 1, } 2 \text { and } 3 \text { mo respectively); Functional } \\
\text { impact (no difference) }\end{array}$ \\
\hline Li et al., $2014 .{ }^{22}$ & Open-label trial & $\begin{array}{c}25-170 \cup(2.5-5 \cup \text { per point }) \\
\text { (BoNT/A) }\end{array}$ & $\begin{array}{l}88 / 88 \text { (at } 2 \mathrm{mo} \text { ) to } \\
34 / 88 \text { (at } 14 \mathrm{mo} \text { ) }\end{array}$ & Responders ( $\geq 50 \%$ reduction), $p=N R$ \\
\hline $\begin{array}{l}\text { Zhang et al., } \\
2014 .^{24}\end{array}$ & $\mathrm{RCT}$ & $\begin{array}{l}25 U \text { and } 75 U \text { at } 20 \text { points } \\
\text { intradermally and/or } \\
\text { submucosally (BoNT/A) }\end{array}$ & $\begin{array}{l}19 / 27(25 \cup) \text { and } \\
25 / 29(75 \cup) \text { from } \\
1^{\text {st }} \text { wk to } 8^{\text {th }} \text { wk }\end{array}$ & $\begin{array}{l}\text { VAS, } p<0.017 \text {; Responders ( } \geq 50 \% \text { reduction), } \\
\qquad<<0.017 \text {; PGIC, } p<0.017\end{array}$ \\
\hline Total & $\begin{array}{l}1 \text { mention; } \\
7 \text { case reports; } \\
2 \text { case series; } \\
5 \text { open-label } \\
\text { trials; } 4 \text { RCT }\end{array}$ & $6 \mathrm{U}$ to $170 \mathrm{U}$ & $213 / 237$ & $\begin{array}{c}\text { Patient report: } 8 \\
\text { VAS: } 9 \\
\text { PAS: } 1 \\
\text { Pain area: } 1 \\
\text { Frequency: } 6\end{array}$ \\
\hline
\end{tabular}

mo: month; MU: mouse units; NR: not reported; PAS: pain analogue scale; PGIC: patient global impression of change; RCT: randomized controlled trial;VAS: visual analogue scale; wk: week.

* patient(s) also had hemifacial spasm

submucosally (total doses were divided by 20 and applied at 20 points). Subjects were excluded if they had coagulopathy or severe heart, liver, kidney or other organ dysfunctions; were at risk if exposed to BoNT/A (e.g., myasthenia gravis); had skin problems at injection sites; had used drugs that damage neuromuscular junctions in the previous seven days; had a significant unstable medical condition or mental disease; had a history of substance abuse; or were pregnant, nursing, planning a pregnancy or using unreliable contraception methods. The
VAS scores of both BoNT/A groups were lower than in the placebo group from the first to the eighth week $(p<0.017)$, and there was no difference between the $25 \mathrm{U}$ and $75 \mathrm{U}$ groups. Also, the number of responders (individuals with a reduction in mean pain score from baseline to endpoint $>50 \%$ ) was higher for the active treatment groups ( $\mathrm{p}<0.017)$ and there was no difference between the groups that received different doses of BoNT/A. The authors concluded that both doses of BoNT/A were effective in the short term. 
The potential of BoNT/A for use in the treatment of TN is attested to not only by the superior design of the randomized placebo-controlled studies, but also by the body of evidence-animal models, case reports, open trials and randomized controlled trials-available to date.

\section{SOME INSIGHTS BEYOND TN: THE THERAPEUTIC EFFECT OF BONT/A IN MIGRAINE, TENSION-TYPE HEADACHE AND "CHRONIC DAILY HEADACHE"}

In a large double-blind, placebo-controlled trial of BoNT/A for migraine, both placebo and BoNT/A proved effective in achieving a $50 \%$ or greater reduction in the number of migraine episodes per 30-day period in relation to baseline in at least $50 \%$ of all patients. However, further analysis of the data revealed that BoNT/A provided a greater benefit for those patients who had $\geq 12$ and $\leq 15$ migraine attacks/month ${ }^{26}$. Conversely, a European placebo-controlled double-blind trial for the treatment of migraine failed to find statistical differences between placebo and BoNT/A groups ${ }^{27}$. A large double-blind, placebo-controlled, parallel-group study of BoNT/A for chronic tension-type headache revealed a small but significant benefit from BoNT/A at a dose of $150 \mathrm{U}$, and more patients in three BoNT/A groups than in the placebo groups had a $50 \%$ or greater decrease in tension-headache days ${ }^{28}$. In placebo-controlled trials of BoNT/A for chronic daily headache, BoNT/A was superior to placebo in decreasing the number of headache days from baseline at some of the time points ${ }^{29,30}$.

\section{SOME INSIGHTS BEYOND TN: THE PLACEBO EFFECT OF BONT/A IN PRIMARY HEADACHES}

The placebo effect of BoNT/A has been well described for more benign conditions such as primary headaches. In a large placebo-controlled dose-finding European trial of BoNT/A for migraine, about 25 to $55 \%$ of the placebo patients experienced a decrease of at least $50 \%$ in migraine frequency ${ }^{27}$. A slightly higher placebo response was found in a similar study conducted in the USA ${ }^{26}$. In a large placebo-controlled dose-finding trial of BoNT/A for chronic tension-type headache, placebo responses at multiple time points over 120 days never reached the $25 \%$ bracket $^{28}$. In the same trial, the placebo also failed to decrease pain severity. In trials of BoNT/A for chronic daily headache, placebo responders rated the improvement from 21 to $23.4 \%^{29,30}$. The average reduction in headache days at day 30 in these trials was less than one headache day for the placebo ${ }^{29,30}$.

\section{FURTHER COMMENTS ON PLACEBO AND THERAPEUTIC RESPONSE IN TN}

Probably the greatest criticism leveled at studies into the use of BoNT/A to treat TN is the lack of a placebo-controlled methodology. This was highlighted by Zakrzewska et al. ${ }^{15}$ and discussed by Sycha et al. ${ }^{31}$, who claimed that the supposed therapeutic effect could be secondary to an expectancy effect, to the natural course of disease or to spontaneous remission. As reported previously, the placebo effect of BoNT/A for primary headache disorders ${ }^{26-30}$ has never reached efficacy rates as high as those described for BoNT/A for TN, even in reports of open-label trials ${ }^{32}$, when this effect is expected to be even higher. In a double-blind, placebo-controlled crossover trial of lamotrigine in a group of patients with refractory TN, patients had poor responses to placebo, and only a single patient out of 13 rated the placebo as "much better" 33 . An analysis of several placebo-controlled studies of carbamazepine for TN showed that only 6 out of 24 placebo patients had a good or excellent response ${ }^{34}$. Similarly, the mean reduction in maximal pain intensity at day 14 reached only $26 \%$ for the placebo, suggesting that the placebo effect for this condition is limit$\mathrm{ed}^{34}$. Furthermore, BoNT/A has been reported to be effective in relieving pain in $\mathrm{TN}$ patients treated for hemifacial spasm in whom an analgesic effect was not expected to occur ${ }^{5,6}$.

Thus, it seems reasonable to conclude that placebo responses are unlikely to have influenced the high response rate to BoNT/A for TN observed in this review. An exception might have occurred in case number four described by Zúñiga et al. ${ }^{14}$, in whom a dramatic decrease in pain occurred minutes after the injections, an effect that can explained by DNIC (diffuse noxious inhibitory control) ${ }^{35,36,37}$.

\section{CONSIDERATIONS ON THE THERAPEUTIC EFFECT OF BONT/A FOR TN}

It may be noteworthy that in the study by Boscá-Blasco et al. ${ }^{11}$ patients treated with BoNT/A for TN were not even receiving co-therapy with membrane-stabilizing drugs and that BoNT/A injections were used as the only therapy. The therapeutic effect of BoNT/A was reported to start from $3.2 \pm 2$ days after the injections, to be significant on day $10^{4,9}$ and to last from 30 days to 6 months ${ }^{4,9,11}$. Follow-up varied from 30 days to 6 months or longer; however, follow-ups longer than 6 months were not described in detail ${ }^{4,9,14}$. Wu et al. ${ }^{21}$, in their randomized controlled trial, showed a reduced mean VAS score in the second week and a reduced frequency of attacks at the end of the first week. In an open-label study to evaluate the long term efficacy of BoNT/A, Li et al. ${ }^{22}$ showed that the prevalence of patients with pain relief $\geq 50 \%$ based on VAS score was 63.6 and $38.6 \%$ at 6 and 14 months, respectively. The varied duration of the therapeutic effect may have been due to differences between patients, the natural history of the disease, the methodology or different placebo effects, although the response to BoNT/A has been reported to be consistent after regularly administered injections, a result that would not be expected for a placebo. Moreover, the reduction in pain documented in patients in a study by our group ${ }^{4}$ had a centripetal or shrinking pattern, 
which would not be expected for a placebo effect (Figure 1). In the same study, TN trigger points disappeared after BoNT/A injections for TN, although this was not described in the report ${ }^{4}$. Lastly, in two studies, five previously refractory patients were able to stop concomitant treatment with membrane stabilizers ${ }^{4.8}$. The argument that the remissions could have been drug-induced or due to the natural history of the disease can be refuted by the fact that these patients continued needing BoNT/A injections to remain symptom-free. Recently, Zúñiga et al. ${ }^{18}$ showed that only those subjects receiving BoNT/A and carbamazepine reported lower average VAS scores at 2 months after injection. This suggests a synergism between both drugs. It is reasonable to suggest that BoNT/A acts by making neuronal sensitization revert to its baseline state and that carbamazepine sustains this effect. In some patients in whom the therapeutic effect lasted up to six months, BoNT/A-triggered remission rather than a placebo effect might have occurred.

\section{BONT/A EFFECT IN SYMPTOMATIC TN}

A pertinent question is whether BoNT/A is effective for both classical and symptomatic TN. Most TN patients in whom BoNT/A was tried had classical TN. Six patients had ipsilateral neurological symptoms, such as hemifacial spasm $^{4,6,11,13}$, and two had contralateral hemifacial spasm but no associated neurological deficit, which in the presence of a vascular loop would differentiate one condition from another. Two of the patients described by Boscá-Blasco et al..$^{11}$ had associated Chiari type I malformation, a finding that would render the cases symptomatic. Yoon et al. ${ }^{38}$ described a patient with neuropathic pain after dental procedures ${ }^{38}$. One of our more recent patients, who was not included in our study, had a severe complication caused by a balloon compression procedure carried out at another center. Her TN persisted, together with hyperesthesia, but she was responsive to BoNT/A procedures. The patient described by Allam et al. ${ }^{8}$ had post-procedure neuropathic pain, which also improved with BoNT/A injections. Stubblefield et al. ${ }^{39}$ reported on the efficacy of BoNT/A for treating TN and other painful conditions in patients with radiation fibrosis after radiotherapy for cancer. Their report did not give details of the criteria upon which their conclusion was based, and the response of both $\mathrm{TN}$ patients and a cervical plexus neuralgia patient were considered together, making it difficult to interpret the results. However, there is new evidence that BoNT/A is effective for other types of neuropathic pain ${ }^{40}$. A neuropathic trigeminal pain model in Rattus norvegicus that used saline for comparison also showed the efficacy of BoNT/ $\mathrm{A}^{41}$.

\section{EXPERIMENTAL BASIS FOR THE IMPROVEMENT OF TN AFTER BONT/A}

BoNT/A may cause rapid improvement in neuropathic pain, as in the experimental study by Cui et al. ${ }^{42}$, in which BoNT/A prevented formalin-induced pain five hours after it was injected in rat hind paws. Thus, the improvement observed by Türk et al. ${ }^{9}$ several hours after BoNT/A injections were administered cannot be considered necessarily to be secondary to a placebo effect, since an early BoNT/A effect can be supported by this recent evidence. However, in humans the therapeutic effect of BoNT/A for TN seems to peak between days 20 and 30 after the injections ${ }^{4}$. Another finding suggesting BoNT/A is effective for TN is that in some patients the pain paroxysms recurred within 90 days, the time required for neuronal sprouting ${ }^{35,36}$. These recurrences were reported to occur even in the presence of associated drug therapy ${ }^{4,6,14}$. In patients who also presented with hemifacial spasm, recurrence of the hemifacial spasm in most cases paralleled that of $\mathrm{TN}$, and both were described as responsive to further injections of BoNT/ $\mathrm{A}^{6,11}$, suggesting that the drug's mechanism of action was similar or shared for both conditions. The supposed mechanism of action of BoNT/A for TN is not within the scope of this paper; however, it has been reported that BoNT/A has an analgesic/anti-neuralgic effect by inhibiting the release of selected neuropeptides and glutamate from primary sensory neurons, directly preventing the sensitization of
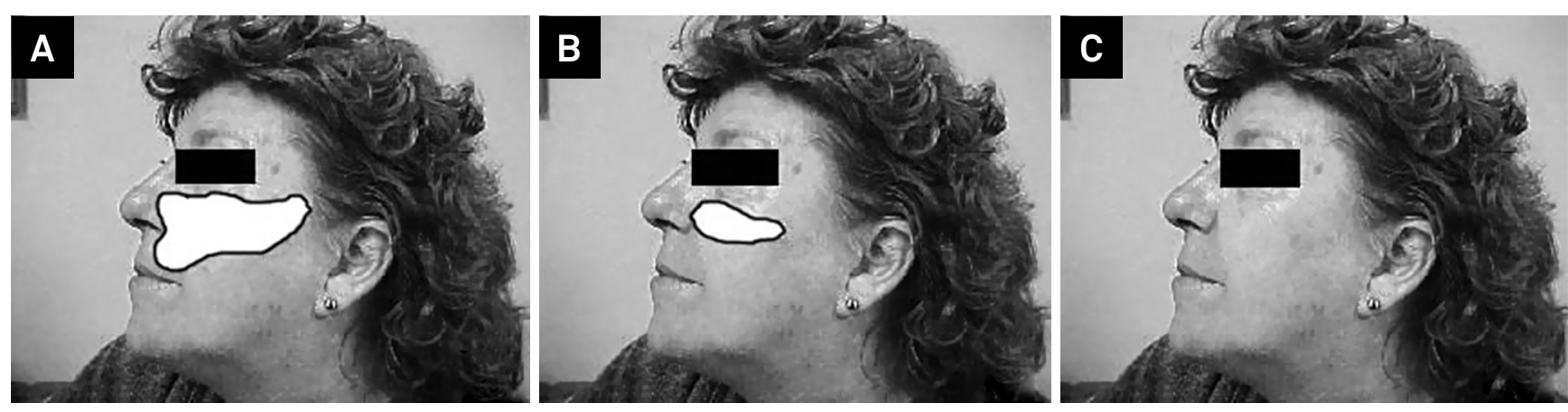

In our previous study ${ }^{4}$, the reduction in pain documented in our patients had a centripetal or shrinking pattern, which would not be expected for a placebo effect. A: before BoNT/A treatment the average pain areas were $2.06 \mathrm{~cm}^{2}, 2.03 \mathrm{~cm}^{2}$ and $2.85 \mathrm{~cm}^{2}$ for $V_{1}, V_{2}$ and $V_{3}$, respectively; $B$ : 10 days after treatment there was a significant reduction in the pain area $\left(1.40 \mathrm{~cm}^{2} ; 1.03 \mathrm{~cm}^{2}\right.$ and $1.54 \mathrm{~cm}^{2}$, respectively); C: patients were almost symptom free 20 to 60 days after treatment (0-0.38 $\mathrm{cm}^{2}, 0.05-0.38 \mathrm{~cm}^{2}, 0-0.56 \mathrm{~cm}^{2}$, respectively).

Figure 1. Reduction in pain: the centripetal or shrinking pattern. 
peripheral pain fibers, indirectly preventing central sensitization and, in dorsal root ganglion cells, inhibiting surface expression of TRPV1 (a vanilloid receptor), which is critical for the release of pain mediators ${ }^{36}$. More recently, evidence that BoNT/A acts centrally has been reported ${ }^{35}$.

\section{Constriction of Rat Infraorbital Nerve as a Model of Trigeminal Neuropathic Pain and the BoNT/A Effect}

Constriction of the infraorbital nerve (a branch of the trigeminal nerve in Rattus norvegicus) appears to be a replicable model of trigeminal neuropathy (Figure 2). Unilateral constriction of the infraorbital nerve or injection of formalin in this region produces peripheral and central sensitization. Unilateral application of BoNT/A produces a reduction in plasma extravasation, a major component of inflammation, and eliminates mechanical allodynia from this region ${ }^{43}$. In animal models in which constriction of the infraorbital nerve produces tactile allodynia with increased expression of FM4-644 and thermal hyperalgesia ${ }^{45}$, both dysfunctions are easily inhibited with prior use of BoNT/A.

\section{Neurobiological mechanisms responsible for the antinociceptive activity of BoNT/A}

After being injected in the subcutaneous tissue, BoNT/A is taken up by endocytosis at nerve terminals of $\mathrm{C}$ fibers and rises by retrograde axonal transport through the trigeminal ganglion to the spinal trigeminal nucleus ${ }^{46}$. One of the main antinociceptive effects of BoNT/A is probably related to its ability to block the transport of nociceptive input to centers modulating nociception ${ }^{43}$.

BoNT/A negatively modulates nociceptive neurotransmitters. Its action can be preganglionic, on CGRP ${ }^{47,48,49}$, substance $\mathrm{P}^{50}$ and glutamate $\mathrm{e}^{51}$, or postganglionic, on synaptic terminations, blocking the release of norepinephrine (NE) and adenosine triphosphate (ATP $)^{52,53}$. A third mechanism may involve internal and external sensory adaptation. In external neural adaptation, BoNT/A reduces secretion of neuroeffector substances from mast cells, blood vessel endothelium and sensory nerve tissue ${ }^{54}$.

One of the main mechanisms responsible for the antinociceptive action of BoNT/A in the treatment of trigeminal neuralgia may be its ability to modulate intrinsic sensory adaptation (by controlling vesicular traffic), which it does by acting directly on transient receptor potential (TRP) ion channels. The TRPs act as integrators of several stimuli and signaling pathways. Dysfunction of these channels contributes to thermal hyperalgesia and allodynia under painful pathological conditions such as trigeminal neuropathy. Among these receptors, those that can potentially be used to treat trigeminal neuralgia include TRPV1, TRPV2, TRPV4, TRPM3, TRPM8 and TRPA $^{55}$. The vanilloid receptor TRPV1 is potentially inhibited after injection of BoNT/A in the region of the first trigeminal branch ${ }^{56}$. The effect of BoNT/A on TRPV1 expression in trigeminal neuralgia leads to reduced expression of CGRP and

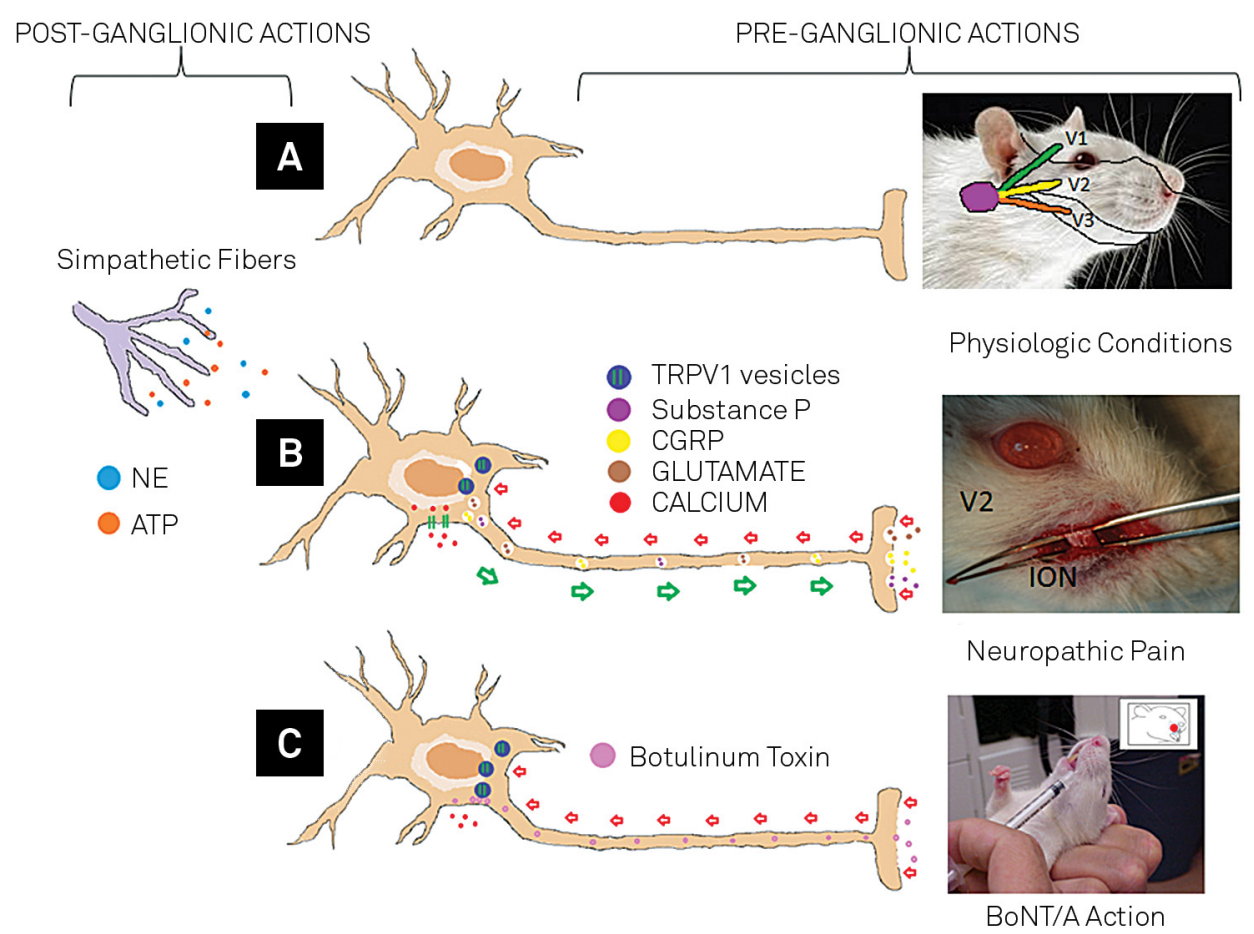

A: Nociception under physiological conditions - focused on the trigeminal nerve and its three branches (V1, V2, and V3); B: Constriction of the exposed infraorbital nerve (ION) - an experimental model of neuropathic pain. Peripheral lesion causing nociceptive activation of transient receptor potential (TRP) channels, a calcium influx to the cell and secondary activation with release of substance P, CGRP and glutamate. Activation of sympathetic fibers with release of norepinephrine (NE) and adenosine triphosphate (ATP); C: Application of BoNT/A with intracellular influx and blocking of TRP expression, inhibiting the release of substance P, CGRP and glutamate $43,44,45,46,47,48,49,50,51,52,53,54,55,56,57,58$.

Figure 2. Mechanisms involved in the genesis of neuropathic pain. 
satisfactory control of facial pain ${ }^{49}$. When blocked, TRPA1 provides a satisfactory reduction in facial mechanical allodynia and cold hyperalgesia ${ }^{57,58}$. To date, no studies showing the effect of BoNT/A on TRPA1 have been published.

\section{FINAL REMARKS}

There is a lack of sufficiently strong evidence to recommend BoNT/A as a therapeutic option with a guaranteed treatment effect. However, as a promising therapy it deserves to be studied further and investigated in additional randomized clinical trials. Further trials have, in fact, been carried out by other centers since the literature review described here was undertaken. We believe BoNT/A can be considered a treatment option and should be tailor-made for the individual on the basis of pain features, previous therapies, associated clinical conditions, recurrence of pain, side effects, contraindications and patient preferences. It is important to remember that there is no consensus regarding when BoNT/A should be indicated for TN. Furthermore, physicians wishing to treat patients with BoNT/A in an off-label fashion should have experience using this neurotoxin for other conditions involving the face, such as hemifacial spasm, or should read the pertinent literature and guidelines carefully to learn about "prohibited areas", thus avoiding serious cosmetic and functional side effects. A lack of experience on the part of the physician administering the treatment can be overcome by strictly following the methodology described ${ }^{4}$, always bearing in mind that intra-oral injections should be avoided to eliminate the risk of infectious complications.

\section{References}

1. International Classification of Headache Disorders: 2nd edition. Cephalalgia. 2004;24(1 suppl):9-160.

2. Manzoni GC, Torelli P. Epidemiology of typical and atypical craniofacial neuralgias. Neurol Sci. 2005;26(2 suppl):s65-7. doi:10.1007/s10072-005-0410-0

3. Nurmikko TJ, Jensen TS. Trigeminal neuralgia and other facial neuralgias. In: Olesen J, Goadsby PJ, Ramadan NM, Tfelt-Hansen P, Welch KMA, eds. The Headaches. 3rd ed. Philadelphia: Lippincott Williams \& Wilkins; 2006: p. 1053-62.

4. Piovesan EJ, Teive HG, Kowacs PA, Della Coletta MV, Werneck LC, Silberstein SD. An open study of botulinum-A toxin treatment of trigeminal neuralgia. Neurology. 2005;65(8):1306-8. doi:10.1212/01.wnl.0000180940.98815.74

5. Wang A, Jankovic J. Hemifacial spasm: clinical findings and treatment. Muscle Nerve. 1998;21(12):1740-7. hdoi:10.1002/ (SICI)1097-4598(199812)21:12<1740\%:AID-MUS17>3.0.CO;2-V

6. Micheli F, Scorticati MC, Raina G. Beneficial effects of botulinum toxin type a for patients with painful tic convulsif. Clin Neuropharmacol. 2002;25(5):260-2. doi:10.1097/00002826-200209000-00006

7. Borodic GE, Acquadro MA. The use of botulinum toxin for the treatment of chronic facial pain. J Pain. 2002;3(1):21-2. doi:10.1054/jpai.2002.27142

8. Allam N, Brasil-Neto JP, Brown G, Tomaz C. Injections of botulinum toxin type a produce pain alleviation in intractable trigeminal neuralgia. Clin J Pain. 2005;21(2):182-4. doi:10.1097/00002508-200503000-00010

9. Türk U, Ilhan S, Alp R, Sur H. Botulinum toxin and intractable trigeminal neuralgia. Clin Neuropharmacol. 2005;28(4):161-2. doi:10.1097/01.wnf.0000172497.24770.b0

10. Volcy M, Tepper SJ, Rapoport AM, Sheftell FD, Bigal ME. Botulinum toxin A for the treatment of greater occipital neuralgia and trigeminal neuralgia: a case report with pathophysiological considerations. Cephalalgia. 2006;26(3):336-40. doi:10.1111/j.1468-2982.2005.00959.x

11. Boscá-Blasco ME, Burguera-Hernández JA, Roig-Morata S, Martinez-Torres I. [Painful tic convulsif and Botulinum toxin]. Rev Neurol. 2006;42(12):729-32. Spanhish.

12. Uluduz D, Karaali-Savrun F, Gunduz A, Kiziltan ME. An unusual case of vascular loop syndrome.J Headache Pain. 2007;8(8):242-4. doi:10.1007/s10194-007-0404-9

13. Felicio AC, Godeiro Junior C, Borges V, Silva SM, Ferraz HB. Bilateral hemifacial spasm and trigeminal neuralgia: a unique form of painful tic convulsif. Mov Disord. 2007;22(2):285-86. doi:10.1002/mds.21202
14. Zúñiga C, Díaz S, Piedimonte F, Micheli F. Beneficial effects of botulinum toxin type A in trigeminal neuralgia. Arq Neuropsiquiatr. 2008;66(3A):500-3. doi:10.1590/S0004-282X2008000400012

15. Zakrzewska JM, Cohen J, Brown J, Alksne J, Gemillion H, Linskey M et al. An open study of botulinum-A toxin treatment of trigeminal neuralgia. Neurology. 2006;66(9):1458-9. doi:10.1212/01.wnl.0000224704.05779.92

16. Cruccu G, Gronseth G, Alksne J, Argoff C, Brainin M, Burchiel Ket al. AAN-EFNS guidelines on trigeminal neuralgia management. Eur $J$ Neurol. 2008;15(10):1013-8. doi:10.1111/j.1468-1331.2008.02185.x

17. Gronseth G, Cruccu G, Alksne J, Argoff C, Brainin M, Burchiel Ket al. Practice parameter: the diagnostic evaluation and treatment of trigeminal neuralgia (an evidence-based review): report of the Quality Standards Subcommittee of the American Academy of Neurology and the European Federation of Neurological Societies. Neurology. 2008;71(15):1183-90. doi:10.1212/01.wnl.0000326598.83183.04

18. Zúñiga C, Piedimonte F, Díaz S, Micheli F. Acute treatment of trigeminal neuralgia with onabotulinum toxin A. Clin Neuropharmacol 2013;36(5):146-50. doi:10.1097/WNF.0b013e31829cb60e

19. Ngeow WC, Nair R. Injection of botulinum toxin type A (BOTOX) into trigger zone of trigeminal neuralgia as a means to control pain. Oral Surg Oral Med Oral Pathol Oral Radiol Endod. 2010;109(3):e47-50. doi:10.1016/j.tripleo.2009.03.021

20. Bohluli B, Motamedi MH, Bagheri SC, Bayat M, Lassemi E, Navi F et al. Use of botulinum toxin A for drug-refractory trigeminal neuralgia: preliminary report. Oral Surg Oral Med Oral Pathol Oral Radiol Endod. 2011;111(1):47-50. doi:10.1016/j.tripleo.2010.04.043

21. Wu CJ, Lian YJ, Zheng YK, Zhang HF, Chen Y, Xie NC et al. Botulinum toxin type A for the treatment of trigeminal neuralgia: results from a randomized, double-blind, placebo-controlled trial. Cephalalgia. 2012;32(6):443-50. doi:10.1177/0333102412441721

22. Li S, Lian YJ, Chen Y, Zhang HF, Ma YQ, He CH et al. Therapeutic effect of Botulinum toxin-A in 88 patients with trigeminal neuralgia with 14-month follow-up. J Headache Pain. 2014;15(1):43. doi:10.1186/1129-2377-15-43

23. Shehata HS, El-Tamawy MS, Shalaby NM, Ramzy G. Botulinum toxin-type A: could it be an effective treatment option in intractable trigeminal neuralgia? J Headache Pain. 2013;14(1):92. doi:10.1186/1129-2377-14-92

24. Zhang H, Lian Y, Ma Y, Chen Y, He C, Xie N et al. Two doses of botulinum toxin type $\mathrm{A}$ for the treatment of trigeminal neuralgia: observation of therapeutic effect from a randomized, double-blind, placebo-controlled trial.J Headache Pain. 2014;15(1):65. doi:10.1186/1129-2377-15-65 
25. Wu C, Lian Y. Botulinum toxin type A for trigeminal neuralgia - we have the prima facie evidence. Cephalalgia. 2012;32(15):1156-7. doi:10.1177/0333102412459578

26. Aurora SK, Gawel M, Brandes JL, Pokta S, Vandenburgh AM. Botulinum toxin type a prophylactic treatment of episodic migraine: a randomized, double-blind, placebo-controlled exploratory study. Headache. 2007;47(4):486-99. doi:10.1111/j.1526-4610.2006.00624.x

27. Relja M, Poole AC, Schoenen J, Pascual J, Lei X, Thompson C. A multicentre, double-blind, randomized, placebo-controlled, parallel group study of multiple treatments of botulinum toxin type A (BoNTA) for the prophylaxis of episodic migraine headaches. Cephalalgia. 2007;27(6):492-503. doi:10.1111/j.1468-2982.2007.01315.x

28. Silberstein SD, Göbel H, Jensen R, Elkind AH, Degryse R, Walcott $\mathrm{JM}$ et al. Botulinum toxin type $\mathrm{A}$ in the prophylactic treatment of chronic tension-type headache: a multicentre, double-blind, randomized, placebo-controlled, parallel-group study. Cephalalgia. 2006;26(7):790-800. doi:10.1111/j.1468-2982.2006.01114.x

29. Mathew NT, Frishberg BM, Gawel M, Dimitrova R, Gibson J, Turkel C. Botulinum toxin type A (BOTOX) for the prophylactic treatment of chronic daily headache: a randomized, double-blind, placebo-controlled trial. Headache. 2005;45(4):293-307. doi:10.1111/j.1526-4610.2005.05066.x

30. Silberstein SD, Stark SR, Lucas SM, Christie SN, Degryse RE, Turkel CC. Botulinum toxin type A for the prophylactic treatment of chronic daily headache: a randomized, double-blind, placebo-controlled trial. Mayo Clin Proc.2005;80(9):1126-37. doi:10.4065/80.9.1126

31. Sycha T, Kranz G, Auff E, Schnider P. Botulinum toxin in the treatment of rare head and neck pain syndromes: a systematic review of the literature. J Neurol. 2004;251(1 Suppl):I19-30. doi:10.1007/s00415-004-1106-8

32. Binder WJ, Brin MF, Blitzer A, Pogoda JM. Botulinum toxin type A (BOTOX) for treatment of migraine. Dis Mon. 2002;48(5):323-35. doi:10.1053/mda.2002.24423

33. Zakrzewska JM, Chaudhry Z, Nurmikko TJ, Patton DW, Mullens EL. Lamotrigine (lamictal) in refractory trigeminal neuralgia: results from a double-blind placebo controlled crossover trial. Pain. 1997;73(2):223-30. doi:10.1016/S0304-3959(97)00104-8

34. McQuay H, Carroll D, Jadad AR, Wiffen P, Moore A. Anticonvulsant drugs for management of pain: a systematic review. BMJ. 1995;311(7012):1047-52. doi:10.1136/bmj.311.7012.1047

35. Antonucci F, Rossi C, Gianfranceschi L, Rossetto O, Caleo M. Long-distance retrograde effects of botulinum neurotoxin A.J Neurosci. 2008;28(14):3689-96. doi:10.1523/JNEUROSCI.0375-08.2008

36. Aoki KR. Future aspects of botulinum neurotoxins. J Neural Transm. 2008;115(4):567-73. doi:10.1007/s00702-007-0758-9

37. PichÉ M, Arsenault M, Rainville P. Cerebral and cerebrospinal processes underlying counterirritation analgesia. J Neurosci. 2009;29(45):14236-46. doi:10.1523/JNEUROSCI.2341-09.2009

38. Yoon SH, Merrill RL, Choi JH, Kim ST. Use of botulinum toxin type A injection for neuropathic pain after trigeminal nerve injury. Pain Med. 2010;11(4):630-2. doi:10.1111/j.1526-4637.2010.00801.x

39. Stubblefield MD, Levine A, Custodio CM, Fitzpatrick T. The role of botulinum toxin type $A$ in the radiation fibrosis syndrome: a preliminary report. Arch Phys Med Rehabil. 2008;89(3):417-21. doi:10.1016/j.apmr.2007.11.022

40. Ranoux D, Attal N, Morain F, Bouhassira D. Botulinum toxin type A induces direct analgesic effects in chronic neuropathic pain. Ann Neurol. 2008;64(3):274-83. doi:10.1002/ana.21427

41. Piovesan EJ, Leite LS, Teive HG, Kowacs PA, Mulinari RA, Radunz V et al. Botulinum toxin type-A effect as a preemptive treatment in a model of acute trigeminal pain: a pre-clinical double-blind and placebo-controlled study. Arq Neuropsiquiatr. 2011;69(1):56-63. doi:10.1590/S0004-282X2011000100012

42. Cui M, Khanijou S, Rubino J, Aoki KR. Subcutaneous administration of botulinum toxin A reduces formalin-induced pain. Pain. 2004;107(1-2):125-33. doi:10.1016/j.pain.2003.10.008
43. Filipović B, Matak I, Bach-Rojecky L, Lacković Z. Central action of peripherally applied botulinum toxin type $A$ on pain and dural protein extravasation in rat model of trigeminal neuropathy. PLoS one. 2012;7(1):e29803. doi:10.1371/journal.pone.0029803

44. Kitamura Y, Matsuka Y, Spigelman I, Ishihara Y, Yamamoto Y, Sonoyama $W$ et al. Botulinum toxin type a $(150 \mathrm{kDa})$ decreases exaggerated neurotransmitter release from trigeminal ganglion neurons and relieves neuropathy behaviors induced by infraorbital nerve constriction. Neuroscience. 2009;159(4):1422-9. doi:10.1016/j.neuroscience.2009.01.066

45. Kumada A, Matsuka Y, Spigelman I, Maruhama K, Yamamoto Y, Neubert JK et al. Intradermal injection of Botulinum toxin type A alleviates infraorbital nerve constriction-induced thermal hyperalgesia in an operant assay. J Oral Rehabil. 2012;39(1):63-72. doi:10.1111/j.1365-2842.2011.02236.x

46. Matak I, Bach-Rojecky L, Filipović B, Lacković Z. Behavioral and immunohistochemical evidence for central antinociceptive activity of botulinum toxin A. Neuroscience. 2011;186:201-7. doi:10.1016/j.neuroscience.2011.04.026

47. Durham PL, Cady R, Cady R. Regulation of calcitonin gene-related peptide secretion from trigeminal nerve cells by botulinum toxin type A: implications for migraine therapy. Headache. 2004;44(1):35-43. doi:10.1111/j.1526-4610.2004.04007.x

48. Meng J, Wang J, Lawrence G, Dolly JO. Synaptobrevin I mediates exocytosis of CGRP from sensory neurons and inhibition by botulinum toxins reflects their anti-nociceptive potential. J Cell Sci. 2007;120(16):2864-74. doi:10.1242/jcs.012211

49. Meng J, Ovsepian SV, Wang J, Pickering M, Sasse A, Aoki KR et al. Activation of TRPV1 mediates calcitonin gene-related peptide release, which excites trigeminal sensory neurons and is attenuated by a retargeted botulinum toxin with anti-nociceptive potential. J Neurosci. 2009;29(15):4981-92. doi:10.1523/JNEUROSCI.5490-08.2009

50. Ishikawa H, Mitsui Y, Yoshitomi T, Mashimo K, Aoki S, Mukuno $K$ et al. Presynaptic effects of botulinum toxin type A on the neuronally evoked response of albino and pigmented rabbit iris sphincter and dilator muscles. Jpn J Ophthalmol. 2000;44(2):106-9. doi:10.1016/S0021-5155(99)00197-5

51. Carlton SM, Hargett GL, Coggeshall RE. Localization and activation of glutamate receptors in unmyelinated axons of rat glabrous skin. Neurosci Lett. 1995;197(1):25-8. doi:10.1016/0304-3940(95)11889-5

52. Verma G. Role of botulinum toxin type-A (BTX-A) in the management of trigeminal neuralgia. Pain Res Treat. 2013;2013:831094. doi:10.1155/2013/831094

53. Mense S. Neurobiological basis for the use of botulinum toxin in pain therapy. J Neurol 2004;251(1 Suppl):I1-7. doi:10.1007/s00415-004-1102-z

54. Borodic GE, Acquadro M, Johnson EA. Botulinum toxin therapy for pain and inflammatory disorders: mechanisms and therapeutic effects. Expert Opin Investig Drugs. 2001;10(8):1531-44. doi:10.1517/13543784.10.8.1531

55. Ferrandiz-Huertas C, Mathivanan S, Wolf CJ, Devesa I, Ferrer-Montiel A. Trafficking of ThermoTRP Channels. Membranes (Basel) 2014;4(3):525-64. doi:10.3390/membranes4030525

56. Shimizu T, Shibata M, Toriumi H, Iwashita T, Funakubo M, Sato H et al. Reduction of TRPV1 expression in the trigeminal system by botulinum neurotoxin type-A. Neurobiol Dis. 2012;48(3):367-8. doi:10.1016/j.nbd.2012.07.010

57. Honda K, Shinoda M, Furukawa A, Kita K, Noma N, Iwata K. TRPA1 contributes to capsaicin-induced facial cold hyperalgesia in rats. Eur J Oral Sci.2014;122(6):391-6. doi:10.1111/eos.12157

58. Gualdani R, Ceruti S, Magni G, Merli D, Di Cesare Mannelli L, Francesconi $\mathrm{O}$ et al. Lipoic-based TRPA1/TRPV1 antagonist to treat orofacial pain. ACS Chem Neurosci 2015;6(3):380-5.. doi:10.1021/cn500248u 